\title{
Shrinking retrograde amnesia ${ }^{1}$
}

\author{
D. FRANK BENSON AND NORMAN GESCHWIND \\ From the Departments of Neurology, University Hospital and Boston \\ Veterans Administration Hospital, and the Aphasia Research Center, \\ Boston University School of Medicine, Boston, Massachusetts, U.S.A.
}

Memory disturbance has long been recognized as a key feature of post-traumatic encephalopathy but one feature of this abnormality, the shrinking of retrograde amnesia, has received scant attention. First described by Russell (1935), and in greater detail by Russell and Nathan (1946), this phenomenon has been neglected by both clinicians and animal experimenters. Recently Deutsch, Hamburg, and Dahl (1966) have demonstrated a similar phenomenon in animal studies. We feel that recognition of shrinking retrograde amnesia is of distinct importance in the clinical appraisal of post-traumatic memory disturbance and in addition has several significant implications for any theory of memory function. We present here a case of posttraumatic memory loss which clearly demonstrates shrinking of retrograde amnesia and discuss both the clinical and theoretical considerations of this phenomenon. Another clinical feature commonly seen in acute traumatic encephalopathy, denial of illness, was also present in this case and will be discussed.

\section{CASE REPORT}

J.R., a 33-year-old right-handed man, was admitted to the University Hospital, Boston, Massachusetts, on 26 November 1965 with a large subcutaneous haematoma in the right temporal-parietal region and deep lacerations across the forehead. He was stuporous but not totally unconscious and there was a mild right hemiparesis. No history was available concerning the cause of injury.

Later additional history was made available. The patient was married and had a family living in Washington, D.C., but two years earlier he had separated from his wife and moved to Boston. He had worked as a bus driver in Washington. Since his arrival in Boston the patient had held two jobs, first as a messenger for a drug store and later as a labourer in a mattress factory. He had finished work on the evening of 25 November and was to have taken a bus trip to Washington. He had not taken the bus and it was assumed, although never definitely

${ }^{1}$ This study was supported in part by grant no. NB-06209 from the National Institute of Neurological Diseases and Blindness to Boston University School of Medicine. proven, that he had gone on a binge. The patient's drinking history was noteworthy; he was not a regular drinker, but on rare occasions he would go on binges lasting several days. He had never needed treatment for alcoholism or its complications. In fact his health had been excellent, his only medical complaints for many years having been minor disturbances of the feet and vision.

During the first hospital week the state of consciousness varied from stupor to semicoma, the right hemiparesis persisted and it was felt that he was aphasic. Radiographs of the skull showed no fracture, lumbar puncture had normal pressure, no cells, and protein of $68 \mathrm{mg}$. per $100 \mathrm{ml}$. An electroencephalogram was abnormal and was considered compatible with a subdural haematoma. A brain scan and a left carotid arteriogram were performed and both were considered to be normal. After one week the patient began to improve, the state of consciousness lightened, the paresis receded and then disappeared but a consistent language disturbance remained. Originally described as pure jargon, the speech later was described as fluent with paraphasia. In addition there was an abnormal behaviour pattern with jocularity, facetiousness, unreliability, and topographical disorientation in the hospital.

He was seen in consultation by members of the Boston University Aphasia Research Unit on 26 December 1965, exactly one month after admission. By that time he was totally free of disturbance of primary motor or sensory functions and there was no evidence of visual field abnormality. He was bright, alert and apparently attentive to the examination but notably distractable. Digit span was recorded at 6 forward. When questions were asked he would respond, not with answers, but with additional questions as to why the examiners were seeking such information. He was totally disoriented for time, giving dates at least three or four years before the time of the examination. When asked to give the date the patient would often evade the question suggesting that the examiners actually knew the date and that he did not need to provide this information. He consistently stated that he was in Washington, D.C., despite being told regularly that he was in Boston. If asked about employment he would reply that he was working as a bus driver in Washington. He was totally unable to remember the names of the physicians and nurses attending him. He could not retain three unrelated words for three minutes. When questioned as to the type of building that he was 
in he would deny that it was a hospital giving a variety of responses some of which were paraphasic. Thus one reply was 'some kind of malingua place-you use it a lot in South America'. If the examiner insisted that the building was a hospital the patient would not argue. If he was immediately asked why he was in the hospital he would either claim that he was visiting or would present a seemingly irrelevant disorder as the cause of hospitalization. On several occasions he stated that he was in hospital because of eye problems; at other times he mentioned difficulties with his feet or legs. He adamantly denied any difficulties in the use of language or memory when specifically questioned concerning these.

His speech was fluent and well articulated but empty of meaning and both literal and verbal paraphasias were present. Comprehension of spoken language was considered normal for ordinary conversation. Repetition and serial speech were normal. He could name simple objects on confrontation but had difficulty if asked to name parts of objects. Thus the crystal on his watch became 'clystal', the watch stem was called a 'spicket', and the lead of a pencil became 'rubber'. He was able to give the names of only three out of $\mathbf{1 0}$ colours. He had great difficulty in presenting word lists; thus he could list the names of only two makes of automobiles in 60 seconds and named only 'ocelot' and 'bear' when asked for a list of animal names. Reading (aloud and for comprehension) was adequate. Orthography was good but the content of his writing was circumlocutory and empty. Right-left orientation and finger localization were intact. He had great difficulty in construction tests, particularly when asked to copy drawings. He was able to calculate.

The patient was transferred to the Boston Veterans Administration Hospital on 27 December 1965 where it was immediately apparent that memory disturbance was the most severe disability. He wandered off the ward, could not find his own bed, would lie down on any bed that was handy, and was frequently seen looking for objects in other patients' bedside stands. At one time he was found wandering in the hospital parking lot, at another time he was watching television three floors below his own ward. Because of this tendency to wander he was transferred to a locked ward on 29 December 1965. During his stay on the locked ward, the jocular, facetious, evasive behaviour, the inability to remember the name of the physicians, the nurses or the hospital, and complete disorientation for time persisted. During this period there was improvement in language so that his speech became more definite and the previously noted paraphasia disappeared. He consistently stated that he was in Washington, D.C., that his last job was that of a bus driver, and he denied illness or memory defect.

An electroencephalogram done during this period was mildly abnormal with suggestion of a slow wave focus in the left posterior temporal region. A brain scan on 20 January 1966 was normal. A pneumoencephalogram on 17 January 1966 showed the size of the lateral ventricles at the upper limits of normal, the fourth ventricle slightly enlarged but the third ventricle of normal size. The left temporal horn was slightly larger than the right but it was not felt that the pneumoencephalogram showed evidence of either mass lesion or hydrocephalus. Spinal fluid taken at that time showed normal pressure, total protein of $48 \mathrm{mg}$. per $100 \mathrm{ml}$., and no cells were present.

The patient's status remained essentially the same except for the improvement in the use of language until about the first of March 1966. During a period of one or two days the ward nurses noted a marked change in his behaviour, for the first time caring about the way he dressed and handled his food, asking them for their names and then correctly using their names later. Re-evaluation was performed on 2 March 1966, at which time he was able to recall three unrelated words after three minutes, to remember the name of the doctor, to remember the name of the hospital after it had been given to him, to recite the names of the ward nurses, and to tell the number and location of the ward. He still manifested a retrograde amnesia since he could not remember moving away from Washington, D.C., but was willing to accept that he was now a patient in a Boston hospital. He no longer denied head injury but stated that he had only recently been told of this injury. He was transferred back to the Neurology Service and had no difficulty now in locating his bed, in getting about the ward and the entire hospital. His behaviour pattern also changed as he became less evasive but remained jocular and facetious. Language evaluation at this time was normal except for minimal evidence of word finding difficulty. He was able to give the names of eight animals in a period of 60 seconds, only slightly below normal levels.

During the remaining period in hospital, the retrograde $\frac{}{\overparen{D}}$ amnesia consistently improved. Thus when he first returned to the Neurology Service he was unable to remember living in the Boston area. Three or four days $\delta$ later he spontaneously recalled separating from his wife and moving to Boston. Several days later he remembered the job that he held when he arrived in Boston and the name of his employer. He was unable to remember any other job in Boston. Within a few days, however, he recalled the second and last job but was still vague as to how long he had worked there. Before discharge the retrograde amnesia had cleared to the point that he remembered quitting work on the day before the injury, approximately 24 hours before admission to the University Hospital. It is likely that the patient began drinking at that time but this was not confirmed by the patient nor any other history available to us.

On the day before discharge an amytal interview was performed. The patient was given approximately $400 \mathrm{mg}$. of sodium amytal intravenously, sufficient to produce both drowsiness and nystagmus. He was questioned about orientation and retested for aphasia. There was a recurrence of the tendency to locate the hospital in Washington, D.C., and to deny that he had suffered a head injury. He again stated that he had been brought to the hospital by his mother because of eye problems. The aphasic deficits noted when he first came to this hospital did not reappear under the influence of amytal. The interview was initiated by two examiners who later were joined by a third person. The day following the interview the patient claimed no memory of the interview and did not remember the third person joining the group despite the fact that he had conversed freely with this examiner 
during the interview. At the time of discharge the patient still had total amnesia for a period starting about 24 hours before admission to hospital at the University Hospital until he suddenly found himself in the locked ward at the Veterans Administration Hospital. He was quite aware of details from that point on. Following discharge the patient returned to Washington, D.C., where he was seen on three occasions in a Veterans Administration clinic. There was no evidence of aphasia or memory deficit so he was discharged from the clinic.

\section{COMMENT}

This case demonstrates several clinical features which deserve discussion. The most dramatic observation was the rather rapid reappearance of the ability to learn new material followed by a slower but progressive shortening in the duration of the retrograde amnesia. This course in the recovery from traumatic memory loss (shrinking retrograde amnesia) has been described previously (Russell and Nathan, 1946) but is not widely recognized in the literature of memory defects. This phenomenon has important implications for both the clinical and experimental evaluation of memory loss.

Changes in memory following head trauma are most often described as consisting of two types of 'amnesia', post-traumatic (anterograde) and retrograde. The first of these, post-traumatic amnesia, is defined as 'the interval during which current events have not been stored' (Russell and Smith, 1961). To the clinician post-traumatic amnesia is most vividly demonstrated when a patient, evaluated long after recovery from head injury, describes total amnesia not only for the period of unconsciousness but for many additional days or weeks, a period during which the patient had apparently regained normal mental function. Older authors described 'recovery of senses' (Jackson, 1932) or of 'vigilance' (Head, 1926) indicating that this was the termination of impaired consciousness but it must be emphasized that a patient may be entirely alert and the 'impairment of consciousness' in post-traumatic amnesia may be confined to an inability to store current events.

The second major division of post-traumatic memory loss is a retrograde amnesia, an inability to recall events preceding the injury. After full recovery the retrograde amnesia is usually quite short, often encompassing only a few seconds before the injury and only rarely exceeding a few minutes. In our patient the permanent retrograde amnesia could not be ascertained since we did not know the exact time of injury, but it could not have exceeded 24 hours. Our estimation of the retrograde amnesia is further complicated because our patient may well have been intoxicated for many hours preceding the trauma.
In patients who suffer a permanent post-traumatic loss of the ability to acquire new memory, however, a much different retrograde amnesia is noted, usually covering several years before the injury. In this latter characteristic the post-traumatic retrograde amnesia is similar to that seen in other disorders with permanent memory loss such as the metabolic Korsakoff's syndrome in which one usually finds a retrograde memory loss of several years before the onset of recognized memory disturbance. An interesting dichotomy is thus present in retrograde amnesia, one type with an amnesic duration of seconds or minutes, and the other with retrograde amnesia lasting at least several years. The patient with shrinking retrograde amnesia thus represents a transitional form between those with long and those with short retrograde amnesia. The observation that permanent retrograde amnesia is usually either very long or very short and that a permanent retrograde amnesia of, let us say a month's duration, is extremely unusual, is of great interest in the theory of memory function and will be discussed in detail.

As post-traumatic amnesia and retrograde amnesia are terms usually used in describing traumatic memory loss another set of terms is indicated for theoretical discussion. The three categories of immediate recall, recent memory, and remote memory have been recognized for many years and have been proved to indicate separate and distinct functions.

Immediate recall (also called immediate memory and short-term memory) has been studied intensively (Brown, 1964). It is described as the ability to retain material for 10 to 30 seconds and is differentiated from the retention of material for several minutes or longer. This type of 'memory' does not entail a permanent coding of the material.

Recent memory can be defined as the ability to retain new material for several minutes or longer. Stated another way, recent memory is the ability to 'learn' new material. It is generally accepted that pathological changes in the limbic system (hippocampal region and mamillary bodies are the most frequently cited) are present in cases with loss of recent memory (Barbizet, 1963). It has also been suggested that these structures must be intact for the consolidation of newly learned material.

Remote memory may be considered to be the ability to recall material learned before the onset of the patient's illness. Included in this previously learned information are basic capabilities such as use of language and numbers, feeding and dressing skills, and significant past history (i.e., birth and marriage dates, career milestones etc.) plus purely learned material (i.e., names of presidents, important historical dates, etc.). 
A period of post-traumatic amnesia clearly corresponds to a period in which there is loss of recent memory function. Such a loss may be limited in time or may be permanent. A corresponding total loss of remote memory function does not occur. Even in the most severely involved patient with a Korsakoff's syndrome much of remote memory is retained. In general the loss for the years immediately preceding the illness is most severe. Remote memory therefore is not involved in as global a fashion as recent memory. It would appear that older, probably overlearned material (e.g., language, the activities of eating, dressing, etc.) is more resistant than more recently acquired material. The inability to recall material acquired in the period preceding the onset of the illness is usually ascribed to the fact that the memory of this material is not 'consolidated' and therefore is more readily wiped out by, for example, a head injury. This explanation carries with it the implication that the process of 'consolidation' may take several years.

It appears to us that the thesis of the abolition of poorly consolidated memory traces as the explanation for retrograde amnesia does not explain the findings of shrinking retrograde amnesia. It is obvious that many of the remote memories which the patient is incapable of recalling in the period immediately following his head injury are not abolished, since the patient does recall them at a later date. The disturbanceis therefore a failure of retrieval rather than a loss of established memories. By contrast the post-traumatic amnesia seems most likely to represent not a failure of retrieval but a failure to establish new memory traces. The permanent post-traumatic retrograde amnesia of seconds, to minutes' duration does, however, probably represent the true abolition of memories not yet consolidated.

According to this view remote memory would fall into three groups. There is a period of seconds to minutes in which a memory is fragile and may be permanently abolished. There is a longer period in which the memory is consolidated but in which retrieval may be impaired. Finally many memories, especially old and overlearned ones, may be retrieved despite influences which abolish the most recently acquired memories and affect the retrieval of many later memories.

It seems possible, furthermore, that the retrieval process depends on the same system that is necessary for the laying down of new memories. This would explain the fact that the shrinking of retrograde amnesia runs generally parallel to the recovery of recent memory function. It would also account for the fact that a patient with a permanent recent memory deficit has a permanent long. retrograde amnesia. Furthermore, the fact that in metabolic Korsakoff's syndromes a permanently long retrograde amnesia is associated with a permanent recent memory loss militates against the assumption that head injury has some unique effect on memory. It would therefore seem probable that those limbic structures which are necessary for the laying down of new memories are also necessary for the retrieval of the more recent or less over-learned older memories.

The permanent long retrograde amnesia of either the metabolic or post-traumatic Korsakoff's syndrome is then a retrieval deficit. It is thus conceivable that by some means it might be possible to make these memories capable of retrieval although this. would not help the patient materially since he would still be suffering from inability to lay down new memories. The consideration must be entertained, however, that in other disturbances of the higher functions, e.g., some aphasic syndromes, retrieval deficits are present, reversal of which, by as yet unknown means, might markedly improve the patient's functional capacities.

Retrograde amnesia and the dramatic phenomenon of shrinkage of retrograde amnesia have important implications for animal experimentation dealing with memory. Until recently the spontaneous. return of memory after a lapse of time following. artificially induced amnesia had never been recorded in animals (Deutsch, 1962). A series of experiments reported by Deutsch et al. (1966) suggested a 'memory loss' which disappeared with time, a finding which agrees with the clinical observations recorded in the present case. This shrinkage of retrograde amnesia was not recognized in many of the earlier animal experiments and theories of memory function based on such incomplete experiments must be viewed with some doubt. Particular question must be raised concerning those studies which purported to find that the process of 'consolidation' was prolonged. It seems likely that most of these studies actually demonstrated difficulties in retrieval.

The late recovery of memory function is of significance clinically. The behaviour problems associated with memory loss demand protective care of the type most often provided by psychiatric institutions. Admission is usually by commitment and recovery of memory function is unexpected, leading to prolonged incarceration. Thus the potentiality of excellent recovery of memory function, even many months after brain injury, deserves emphasis.

This case demonstrated another dramatic phenomenon, denial of illness, which has been recognized and discussed for many years. It has been suggested by some that a parietal lesion was necessary for such denial (Schilder, 1934; Nielsen, 1938), by others that 
denial was a manifestation of clouding of consciousness (Spillane, 1942; Sandifer, 1946), or that denial of major neurological defect suggested impaired recognition of body scheme (Gerstmann, 1942; Critchley, 1953). Weinstein and Kahn (1955) suggest that denial is actually motivated and represents a psychological defence mechanism occurring in a patient with widespread dysfunction of the nervous system who is unwilling to accept the presence of a major deficit.

The present patient had clear denial of illness when first seen and the denial persisted, essentially without change until the post-traumatic amnesia cleared. During this time the patient adamantly refused to admit head injury, language disorder, or memory loss, and if pushed by interrogation would state that he was in the hospital because of visual difficulty or foot trouble. There was consistent disorientation for time, most often evasive, but if firmly pushed the patient would give a date several years before the time of his injury. He consistently insisted that he was in Washington, D.C., his former home.

Taken out of context these findings could be considered motivated with the patient actively denying his obvious defects. It seems preferable, however, to describe this as confabulation, an attempt by the patient to fill a void in his knowledge of present occurrences with past knowledge. This fits a current theoretical view (see, for example, Barbizet, 1963) which suggests that confabulation is an attempt on the part of a patient, unable to learn new information, to provide requested information from the only source available to him, his past memory. Our patient continued to deny his neurological defects and remained disoriented until he rather rapidly regained normal recent memory function at which time all denial symptoms disappeared. In our opinion the denial and memory loss were probably results of the same process. Thus it is not entirely correct to state that our patient denied his illness but would be more accurate to say that he was unable to remember the present difficulty and attempted to fill this void by providing older, previously overlearned information.

A defect in word finding was clearly demonstrated in this patient and was such a prominent feature in the early part of the hospital course that at least one competent examiner considered the major difficulty to be anomic aphasia. Weinstein and Kahn noted word finding defects in many of their patients who denied illness. In their opinion, the naming defect appeared to be more pronounced for hospital oriented items (i.e., thermometer, stethoscope, urinal, etc.) than for other objects. They suggested that this was not a true naming defect and that the 6 'paraphasia' demonstrated in these patients was truly a non-aphasic misnaming of stress-producing items. In the present case this theory cannot be substantiated. It is true that our patient had difficulty in naming hospital oriented items but he had just as much difficulty naming other items. While it would be tempting to link his memory disturbance with his anomia it is difficult to do so since our experience as well as that of others confirms the existence of severe memory loss in adults without anomic disorders. It is most likely that our patient's anomic disturbances were secondary to cerebral contusion.

Finally it is worth discussing the results demonstrated by the amytal interview. This technique was used by Russell and Nathan and was also used extensively by Weinstein and Kahn. In the present case we were interested mainly in the possibility of reappearance of aphasic symptoms so we did not attempt to demonstrate regrograde amnesia nor did we realize during the interview that we had actually produced a period of recent memory loss. However, in an interview with the patient the following day it was quite apparent that he had no memory whatsoever of occurrences during the interview and in fact did not realize that a third person had joined the interview team, a person whom heknew very well, and who had talked to him during the interview. Quite possibly better observation on our part would have demonstrated a distinct reappearance of retrograde amnesia but even our limited observations suggested its recurrence. One of the most significant parts of the interview was the reappearance of the denial of illness. The patient strongly and adamantly denied that he was in the hospital because of any head or brain injury and again told the story of being brought to the hospital by his mother because of eye problems. Before the amytal interview the patient was no longer telling this story and following the amytal interview he was quite aware of the reason for hospitalization. Thus with amytal we were able to produce many of the findings that were seen during the acute state of the disorder and suggest that one of the effects of amytal is to impair the function of those regions involved in new learning and in the retrieval of more recent (less overlearned) past memories.

\section{SUMMARY}

A case of post-traumatic encephalopathy with a three month period of post-traumatic amnesia has been presented. Particular attention was given to the striking shrinking of retrograde amnesia which occurred after recovery of recent memory function had taken place and to the denial of illness seen in the course of the illness. 
Two types of permanent retrograde amnesia are demonstrated by this case and other cases of memory loss, a long retrograde amnesia of several years' duration and a much shorter retrograde amnesia, usually of less than one day's duration. Retrograde amnesia of intermediate length appears to occur only during the period of shrinking of the retrograde amnesia. Long-term retrograde amnesia is associated with a continued defect in recent memory whereas short-term retrograde amnesia is present only in individuals with intact ability to learn new information. The fact that memories that are unavailable during long-term retrograde amnesia can return without a process of relearning shows that these memories are not lost, but that the ability to retrieve this material is lost during long-term retrograde amnesia. Thus it is suggested that the same anatomical substrate necessary for laying down new memories is probably necessary for retrieval of less overlearned or more recently acquired past memories. This has significant implications for animal experimentation dealing with memory, particularly those concerned with the time course of memory 'consolidation'.

Denial of illness was notable in this case up to the point that recent memory function returned at which time the denial abruptly ceased. This suggests that the denial was actually a confabulation caused by inability to learn new information, specifically the details of the present illness. After recovery of memory function we were able to reproduce the denial of illness, the recent memory defect and lengthening of the retrograde amnesia by use of intravenous amytal, again suggesting the linkage of these disturbances.

The authors wish to acknowledge the valuable assistance of Donald Urrea, M.D., in the clinical evaluation of this case.

\section{REFERENCES}

Barbizet, J. (1963). Defect of memorizing of hippocampal-mammillary origin: a review. J. Neurol. Neurosurg. Psychiat., 26, 127-135.

Brown, J. (1964). Short-term memory. Brit. med. Bull., 20, 8-11.

Critchley, M. (1953). The Parietal Lobes. Arnold, London.

Deutsch, J. A. (1962). Higher nervous function: The physiological bases of memory. Ann. Rev. Physiol., 24, 259-286.

-, Hamburg, M.D., and Dahl, H. (1966). Anticholinesteraseinduced amnesia and its temporal aspects. Science, 151, 221-223.

Gerstmann, J. (1942). Problem of imperception of disease and of impaired body territories with organic lesions: relation to body scheme and its disorders. Arch. Neurol. Psychiat., 48, 890-913.

Head, H. (1926). Aphasia, and Kindred Disorders of Speech. University Press, Cambridge.

Jackson, J. H. (1931-32). Selected Writings of John Hughlings Jackson, edited by J. Taylor. Hodder \& Stoughton, London.

Nielsen, J. M. (1938). Gerstmann syndrome: finger agnosia, agraphia, confusion of right and left and acalculia: comparison of this syndrome with disturbances of body scheme resulting from lesions of the right side of the brain. Arch Neurol. Psychiat., 39, 536-560.

Russell, W. R. (1935). Amnesia following head injuries. Lancet, 2 , $762-763$.

300.

- and Smith, A. (1961). Post-traumatic amnesia in closed head injury. Arch. Neurol. (Chic.), 5, 4-17.

Sandifer, P. H. (1946). Anosognosia and disorders of body scheme. Brain, 69, 122-137.

Schilder, P. (1934). Localization of the body image (postural model of the body). Res. Publ. Ass. nerv. Dis. 13, 466-484.

Spillane, J. D. (1942). Disturbances of the body scheme: anosognosia and finger agnosia. Lancet, 1, 42-44.

Weinstein, E., and Kahn, R. (1955). Denial of Illness. Thomas, Springfield, Illinois. 